\title{
Congenital human toxoplasmosis caused by non-clonal Toxoplasma gondii genotypes in Argentina
}

\author{
Lais Pardini ${ }^{\mathrm{a}, \mathrm{b}, *}$, Mariana Bernstein ${ }^{\mathrm{a}, \mathrm{b}}$, Liliana A. Carral ${ }^{\mathrm{c}}$, Federico J. Kaufer ${ }^{\mathrm{c}}$, Andrea Dellarupe ${ }^{\mathrm{a}, \mathrm{b}}$, \\ María L. Gos $^{\mathrm{a}, \mathrm{b}}$, Lucía M. Campero ${ }^{\mathrm{a}, \mathrm{b}}$, Gastón Moré ${ }^{\mathrm{a}, \mathrm{b}}$, Matías T. Messina ${ }^{\mathrm{c}}$, María V. Schneider ${ }^{\mathrm{c}}$, \\ Cristina B. Freuler ${ }^{c}$, Ricardo A. Durlach ${ }^{c}$, Juan M. Unzaga ${ }^{a}$, María C. Venturini ${ }^{a}$ \\ ${ }^{a}$ Laboratorio de Inmunoparasitología, FCV-UNLP, La Plata, Argentina \\ ${ }^{\mathrm{b}}$ CONICET, Argentina \\ ${ }^{\mathrm{c}}$ Centro de Toxoplasmosis, Hospital Alemán, Buenos Aires, Argentina
}

\section{A R T I C L E I N F O}

\section{Keywords:}

Toxoplasmosis

Congenital

Humans

Genotypes

Isolates

nPCR-RFLP

\begin{abstract}
A B S T R A C T
Toxoplasmosis, a worldwide distributed zoonosis, can be transmitted congenitally affecting fetuses and developing variable clinical signs. Different Toxoplasma gondii genotypes and infective dose are related factors with different clinical manifestations. Several studies indicate that atypical strains could produce more severe clinical manifestations compared to typical strains. Umbilical cord blood $(n=37)$ and placenta $(n=19)$ were collected at birth from women with acute $T$. gondii infection and processed for isolation by mice bioassay. Six isolates were obtained and identified as TgHm14-4Arg, TgHm15-02Arg, TgHm16-01Arg, TgHm16-02Arg, TgHm17-01Arg and TgHm17-02Arg. Three genotypes described previously on Toxo-DB were identified: \#138 identified in chickens from Brazil, \#182 isolated from eared doves from Brazil, \#14 from wallaby kangaroos and chickens from Argentina, chickens from Brazil, Colombia, Chile and Venezuela, cats and dogs from Brazil and Colombia and also coyotes from USA indicating worldwide distribution of these genotypes. Two new allele combinations were obtained showing high genotypes diversity in Argentina. Four of the isolates (TgHm14-4Arg, TgHm15-02Arg, TgHm16-01Arg, TgHm16-02Arg) and two of them (TgHm17-01Arg, TgHm17-02Arg) produced chronic and acute infections in mice, respectively. Until now, seven T. gondii isolates have been obtained from humans in Argentina, and all were atypical or non-clonal genotypes. The identification of atypical strains causing congenital toxoplasmosis and circulating in our region, make important to perform the serological screenings according Argentine Consensus of Toxoplasmosis and to apply and monitoring treatments earlier in pregnancy. To achieve this aim, it is necessary to inform general population about $T$. gondii infection, diagnostics and control measures. These results should serve to generate awareness about congenital toxoplasmosis in South America.
\end{abstract}

\section{Introduction}

Toxoplasmosis is a worldwide distributed zoonosis caused by the Apicomplexa protozoan parasite Toxoplasma gondii, which can infect warm blooded animals including human beings [1]. Humans can acquire the infection by the ingestion of raw or undercooked meat or derivates containing tissue cyst, mainly from sheep, goats and pigs and water or vegetables contaminated with oocysts delivered in felids feces [1]. Infection during pregnancy could result in passage of parasites (tachyzoites) via placenta to the fetal tissues. This route has been identified as congenital or vertical transmission, producing a wide spectrum of fetal lesions, mainly in neuromuscular system and eyes.
Clinical signs are unusual in immunocompetent people, however immunocompromised patients and newborns with congenital infection could manifest variably signs including encephalitis, pneumonia and ophthalmologic disease. Neurological signs in babies with congenital infection is more severe when transmission occurs early on pregnancy [2-5]. Positive reactions in serological studies provide indirect evidence of T. gondii infection and determine that more than one third of the worldwide population is infected [6]. Serological follow-up of pregnant women is important to detect potential primary infection during gestation and to apply an early treatment to prevent vertical transmission $[7,8]$. Specific pharmacological treatment should be provided to newborns with diagnosis of congenital toxoplasmosis during

\footnotetext{
* Corresponding author at: Laboratorio de Inmunoparasitología, Facultad de Ciencias Veterinarias, Universidad Nacional de La Plata, calle 60 y 118 , 1900 La Plata, Argentina.

E-mail address: laispardini@fcv.unlp.edu.ar (L. Pardini).
} 
the first year of life, specially indicated to avoid severe chorioretinitis which is frequently named Ocular Toxoplasmosis (OT) [9,10]. Previous serological studies in Argentina showed a T. gondii seroprevalence of 47.3\% in pregnant women [10]. A recent study in Argentina indicates a transplacental transmission rate of 5.4\% [7]. Generally, isolation of $T$. gondii is more frequent from symptomatic cases of congenital toxoplasmosis or immunosuppressed patients [9]. Molecular studies have been improved and allowed the identification of T. gondii genotypic characteristics. Population structure of $T$. gondii is complex, being predominant the clonal-types in Europe and North America while nonclonal or atypical genotypes are wide distributed in other continents such South America [11,12]. Clonal type II, which predominates in Europe, showed a low virulence and rarely caused severe signs or disease. Additionally, this biological behavior has been used as base for the implementation of European control programs. During the last years, better knowledge about the relationship between genotypes and virulence have aroused [13]. Clonal type I isolates showed the lower frequency of detection from congenital cases but are considered the most virulent strains [13]. It has been shown that non-clonal genotypes exhibited different virulence degrees, being regularly higher virulent than clonal type II [9]. Unfortunately, most of South American control programs are similar to the Europeans, following a paradigm based on clonal types. Recently, a new paradigm was proposed, because severe congenital toxoplasmosis was related to atypical genotypes [14] and higher frequency and severity of OT in Brazil and Colombia than in North America and Europe, associated with presence of virulent strains identified genetically as atypical or non-clonal has been reported [15-18].

In a survey on congenital toxoplasmosis performed in Argentina 24/ 67 newborns where identified as vertically infected by serology and one case was detected only by mouse bioassay and PCR, indicating the importance of using a combination of diagnostic methods in congenital toxoplasmosis [19]. In other countries, T. gondii DNA was detected in $9.9 \%$ to $19.8 \%$ of cases when umbilical cord blood was analyzed by PCR, and most researchers emphasize that vertical transmission is underreported when only serological analysis is performed [7,20,21].

Several atypical isolates have been reported in ToxoDB (http:// toxodb.org/toxo/), especially from South America. In Sao Paulo state, the isolates identified as \#6, 65 and 71 in ToxoDB are the most frequently detected in domestic and wild animals as well as in human beings [22]. Genotype \#6 (predominance type I alleles) was also identified in humans from Belgium, Cameroon, France, Gabon and Turkey, while genotype \#65 is frequently found in humans from Brazil [22] and also isolated from cats and chickens [17]. In Argentina T. gondii isolates were obtained from many domestic and zoo animals, detecting several non-clonal allele combinations as well as clonal types II and III [1,23-26]. To the best of our knowledge, only one T. gondii isolate from a human placenta was obtained in Argentina [27].

The aim of this study was to isolate and genotype $T$. gondii strains from umbilical cord blood and placenta obtained from acute congenital toxoplasmosis cases in Argentina.

\section{Materials and methods}

\subsection{Cases and samples}

Between 2014 and 2017 a total of 19 placentas and 37 umbilical cord blood (UCB) were sampled at birth from women serologically diagnosed with acute toxoplasmosis at Hospital Alemán de Buenos Aires (HA). From six of these cases T. gondii was successfully isolated and reported in this study. Women came from CABA (Ciudad Autónoma de Buenos Aires) and surroundings. Acute toxoplasmosis was detected when serological routine diagnosis was performed according to Argentine Consensus of Toxoplasmosis [10]. Blood samples from mothers were collected during gestation and at birth. Babies blood samples were also taken at birth for serological analysis. All mothers were diagnosed at end of gestation with the exception of mother of case 4 who received specific treatment during second and third gestation trimester according to Argentine Consensus of Toxoplasmosis [10].

Umbilical cord blood from babies (B) B1-B4, and placenta from B4, B5 and B6 were collected at birth and processed for isolation by mice bioassay.

\subsection{Serology}

Serum samples were analyzed at HA by Sabin Feldman dye test (SF), assessment of immunosorbent agglutination assay (ISAGA)-IgM, ISAGA-IgA, ISAGA-IgE and avidity test to determine antibodies to $T$. gondii and establish infection status according to recommendations of the Argentine Consensus of Congenital Toxoplasmosis [10].

\subsection{Bioassay in mice}

Umbilical cord blood samples were centrifuged to separate the plasma, washed 3 times with sterile saline solution (SS) and each placenta sample was treated with trypsin $1 \%\left(2 \mathrm{~h}-37^{\circ} \mathrm{C}\right)$, washed 3 times with SS and filtered through gauze to finally resuspended with SS and antibiotics, at the same way as described by Carral et al. [19].

Mice (NMRI Swiss) were inoculated intraperitoneally (IP) as follows: 3 mice (M1-M3) with CB from B1, 2 mice (M4, M5) with CB from B2 and 2 mice (M6, M7) with CB from B3. Two mice (M8, M9) were inoculated with $\mathrm{CB}$ and one (M10) with placenta from B4. Three mice (M11-M13) with placenta from B5 and other three (M14-M16) with placental samples from B6. After 30 days post inoculation (dpi) mice were sacrificed independently of compatible toxoplasmosis signs and blood and central nervous system (CNS) samples were obtained. If any mice develop severe clinical signs earlier than 30 dpi were humanely sacrificed. Mice CNS samples were smashed with saline solution and tissue cysts were looked forward by optical microscopic observation. Isolates were maintained by mice passage, 10 tissue cysts per mouse were inoculated intraperitoneally into 2 new mice. Peritoneal washing was performed to determine presence of tachyzoites for each died or sacrificed mouse between 6 and 10 dpi. Peritoneal fluids were inoculated in VERO cell cultures, with RPMI 1640 (Gibco) and 3\% fetal calf serum (NATOCOR) at LAINPA-FCV-UNLP. Parasites were stored in liquid nitrogen at $-196^{\circ} \mathrm{C}$.

\subsection{Mice serology}

Sabin Feldman dye test was performed to detect specific antibodies to $T$. gondii in mice sera as previously [27]. Positive and negative sera were used as controls.

\subsection{PCR diagnosis and genotyping of T. gondii isolates}

Cord blood from the six babies was analyzed by RT-PCR for gen B1 at HA according to Carral et al. 2018 [19]. A small sample of placenta was received and completely used for bioassay.

DNA from brain of mice and peritoneal fluid with tachyzoites was extracted using a commercial kit (Promega Wizard Genomic DNA Purification Kit) according to manufacturer's instructions, along with an extraction control sample (only kit solutions). Polymerase chain reaction (PCR) for T. gondii was performed using specific primers TOX5TOX8 with a protocol previously described [26]. Toxoplasma gondii DNA (RH strain) from cell cultured tachyzoites, and DNA extraction control sample were used as positive and negative controls, respectively along with a no template control sample. Amplicons were reveled on $1.5 \%$ agarose gels and stained with SYBR-Safe (Invitrogen).

Genotyping was performed using nested-PCR (n-PCR) followed by restriction fragment length polymorphism (RFLP) analysis. Extracted DNA was amplified by n-PCR for SAG1, 5'3'SAG2, nSAG2, SAG3, BTUB, GRA6, c29-2, c22-8, L358, PK1 and Apico markers [26,28-30]. DNA 
Table 1

Congenital toxoplasmosis cases description and results of serological tests.

\begin{tabular}{|c|c|c|c|c|c|c|c|}
\hline Cases & Treatment & PCR in ucb & Sabin Feldman titer & ISAGA M & ISAGA A & ISAGA E & Avidity test \\
\hline M 1 & No & & 16,384 & Positive & Positive & Negative & nd \\
\hline B 1 & & Negative & 4096 & Positive & Positive & Negative & \\
\hline M 2 & No & & 4096 & Positive & Positive & Positive & low \\
\hline B 2 & & Positive & 4096 & Positive & Positive & Negative & \\
\hline M 3 & No & & 4096 & Positive & Positive & Negative & nd \\
\hline B 3 & & Negative & 1024 & Positive & Positive & Negative & \\
\hline M 4 & Yes & & 1024 & Positive & Negative & nd & nd \\
\hline B 4 & & Negative & 1024 & Negative & Negative & nd & \\
\hline M 5 & No & & 4096 & Positive & Positive & Positive & Low \\
\hline B 5 & & Positive & 4096 & Positive & Positive & Positive & \\
\hline M 6 & No & & 16,384 & Positive & Positive & Positive & Low \\
\hline B 6 & & nd & 16,384 & Positive & Positive & Positive & \\
\hline
\end{tabular}

M: mother, B: baby, nd: not determined, ucb: umbilical cord blood.

from in vitro cultured T. gondii strains RH, ME49 and NED was used as positive control for clonal types I, II and III respectively and from $\mathrm{TgCgCa} 1$ and $\mathrm{TgCatBr} 64$ strains were used as controls to differentiate alleles u-1 and u2 for PK1 marker. Digestion products were visualized after electrophoresis with $2.5 \%$ agarose gels for all markers except for Apico where a $3 \%$ gel was used, and stained with SYBR-safe using a 100 bp standard (Cien marker, Biodynamics).

\section{Results}

Acute toxoplasmosis was diagnosed in all women by serological tests. Detailed serological results from mother and newborns are showed in Table 1. Babies B1, B3, B4 and B5 were asymptomatic while B2 developed chorioretinitis and B6 developed hydrocephaly, ventriculomegaly and ascites. Specific treatment was indicated for all babies.

Mice M11-M16 died after 8 dpi and M3-M10 were sacrificed at 30 dpi independently of compatible toxoplasmosis signs. M1 and M2 died after 2 dpi and without compatible findings of toxoplasmosis and the material was discarded. Specific $T$. gondii antibodies were detected by SF: M3 (1/16834), M4 (1/16384), M7 (1/16384), and M10 (1/16384); M5, M6, M8 and M9 were seronegative at the end of bioassay. Due to the short time between inoculation and death the M11-M16 were not processed for antibody detection. Tissue cysts were observed in brain of seropositive mice (M3, M4, M7, M10) which were sacrificed 30 dpi. Peritoneal exudates of M11-M16 presented abundant tachyzoites. Six isolates (one for each mother-newborn) were obtained and denominated as TgHm14-4Arg from M3 belongs to B1, TgHm15-02Arg (B2) from M4, TgHm16-01Arg (B3) from M7, TgHm16-02Arg (B4) from M10, TgHm17-01Arg (B5) from M11-M13 and TgHm17-02Arg (B6) from M14-M16 (Table 2). Isolates were maintained by mice passage at HA and by mice and cell culture passages at LAINPA-FCV-UNLP.

Toxoplasma DNA was detected on B2 and B5 cord blood analyzed by RT-PCR. Specific T. gondii DNA was detected by PCR in CNS from 1 mouse inoculated with each B1-B4 and all mice inoculated with B5 and B6. All parasite isolates were positive in T. gondii specific PCR.
Genotyping results are detailed on Table 3, all isolates were characterized as atypical or non-clonal for the markers used in this study. Allele combinations were compared with genotypes reported in ToxoDB and a haplotype/genotype ID was provided (Table 3).

\section{Discussion}

Most of human $T$. gondii isolates were obtained from symptomatic cases of congenital toxoplasmosis or immunosuppressed patients [9]. In the present study, we focus on to obtain isolates from pregnant women without clinical signs and with acute toxoplasmosis detected by serological methods $[9,10]$. Umbilical cord blood and placenta samples were processed by mice bioassay, allowing the parasites isolation in six cases. The parasites were confirmed as T. gondii by specific PCR. Only mother 4 received specific treatment during second and third gestation trimester, related to the early serological diagnose on pregnancy in this case. Interestingly, on this case (B4) the specific treatment was not enough to control completely the infection because viable parasites were isolated from placenta. These results emphasize the importance of carefully monitoring mother treatment until the end of pregnancy as well as in the babies, and also highlight the usefulness of the mice bioassays for diagnosis and treatment evaluation.

All the isolates were characterized as non-clonal types and were denominated as TgHm14-4Arg, TgHm15-02Arg, TgHm16-01Arg, TgHm16-02Arg, TgHm17-01Arg and TgHm17-02Arg. Most markers showed type III alleles, which is frequently identified for $T$. gondii genotyping from isolates from South American countries [11,12,31]. TgHm14-4Arg genotype showed a genotype identified as \#138 in ToxoDB, which was previously identified in chickens from Brazil [17]. TgHm15-02Arg showed the same allele combination reported as \#182, which was isolated from eared doves (Zenaida auriculata) from Brazil [32].

TgHm17-01Arg and TgHm17-02Arg (incomplete for 5'3'SAG2) were identified as \#14 and \#14 likely, respectively, similar to isolates from wallaby kangaroos and chickens from Argentina and also chickens from other South American countries (Brazil, Colombia, Chile and

Table 2

Mice bioassay results.

\begin{tabular}{|c|c|c|c|c|c|c|c|}
\hline \multirow[t]{2}{*}{ Case } & \multicolumn{2}{|c|}{ Inoculated mice } & \multirow[t]{2}{*}{ Chronic infection } & \multirow[t]{2}{*}{ Acute infection } & \multirow[t]{2}{*}{ Mortality } & \multirow[t]{2}{*}{ Seropositive } & \multirow[t]{2}{*}{ Isolate identification } \\
\hline & ucb & $\mathrm{p}$ & & & & & \\
\hline В 1 & 3 & & $1 / 3$ & - & - & - & TgHm14-4Arg \\
\hline В 2 & 2 & & $1 / 2$ & - & - & $1 / 2$ & TgHm15-02Arg \\
\hline B 3 & 2 & & $1 / 2$ & - & - & $1 / 2$ & TgHm16-01Arg \\
\hline B 4 & 2 & 1 & $1 / 3(\mathrm{p})$ & - & - & $1 / 3(\mathrm{p})$ & TgHm16-02Arg \\
\hline В 5 & & 3 & - & $3 / 3$ & $100 \%$ & - & TgHm17-01Arg \\
\hline В 6 & & 3 & - & $3 / 3$ & $100 \%$ & - & TgHm17-02Arg \\
\hline
\end{tabular}

B: baby, ucb: umbilical cord blood, p: placenta. Chronic infection $=T$. gondii CNS tissue cysts; Acute infection $=$ peritoneal tachyzoites. 
Table 3

T. gondii genotyping results obtained from isolates from human congenital toxoplasmosis cases in Argentina.

\begin{tabular}{|c|c|c|c|c|c|c|c|c|c|c|c|c|}
\hline STRAIN ID & TOXODB ID & SAG1 & $5^{\prime} 3^{\prime}$ SAG2 & SAG2 & BTUB & GRA6 & SAG3 & PK1 & L358 & $\mathrm{C} 22-8$ & C29-2 & Apico \\
\hline TgHm14-4Arg & \#138 & $\mathrm{u}-1$ & III & III & III & III & III & III & III & III & I & III \\
\hline TgHm15-02Arg & \#182 & I & III & III & III & III & III & I & I & III & I & III \\
\hline TgHm16-01 Arg & New & I & nd & III & III & III & III & II & I & III & III & III \\
\hline TgHm16-02 Arg & New/\#287 & $\mathrm{u}-1$ & nd & III & III & III & III & III & III & III & III & I \\
\hline TgHm17-01 Arg & $\# 14$ & I & III & III & III & III & III & III & III & III & I & III \\
\hline TgHm17-02 Arg & Likely \#14 & I & nd & III & III & III & III & III & III & III & I & III \\
\hline
\end{tabular}

nd: not determined.

Venezuela), cats and dogs from Brazil and Colombia and coyotes from USA, indicating a wide distribution of this genotype [11,12,33-35]. Both isolates with genotype \#14 or \#14 likely from present study induced death of mice about a week post inoculation, suggesting an aggressive behavior and/or a high infective dose in the inoculated material. Additionally, TgHm17-02Arg was obtained from a newborn which developed severe lesions, which agrees with the apparent high virulence of this genotype in mice bioassay. This could be associated with parasite virulence as well as individual host susceptibility including poor cellular immune response. Altogether, it is possible to assume that genotypes \#14 or \#14 likely is more virulent than clonal types II and III isolates.

On the other hand, mice infected with isolates TgHm14-4Arg, TgHm15-02Arg, TgHm16-01Arg and TgHm16-02Arg developed chronic infection without clinical sings, indicating low virulence and/or lower infective dose. TgHm16-01Arg (incomplete for 5'3'SAG2), and $\mathrm{TgHm}$ 16-02Arg (\#287) could represent former reported genotypes or even "new" genotypes which were not previously recorded in ToxoDB [31]. Previous studies have claimed the need of complete genotyping in order to reach trustable comparisons [9]. Additionally, in a recent comparative study performed with several T. gondii Argentinean isolates, some of them formerly considered as clonal turned as non-clonal when all the genetic markers were analyzed [31]. Among these isolates was included the $T$. gondii isolate from a human placenta considered as clonal type II (\#1), which in fact represents a non-clonal variant of type II [31]. Considering this information, all so far T. gondii isolates from humans in Argentina represents non-clonal allele combinations. These atypical genotypes with predominance of type III alleles are frequent in South America, including Argentina [12,31], however are different to the predominant genotype \#65 in humans from Brazil [11,17,22] and \#6 from Belgium, Brazil, Cameroon, France and Turkey (ToxoDB) [36-38]. Therefore, it would be necessary enhance the sampling from human cases to increase the knowledge about the epidemiology of toxoplasmosis in Argentina. As mentioned before, isolates with atypical genotypes are frequently associated to higher severity of lesions, suggesting a higher virulence than clonal types [13]. In the present study fetal lesions and mice virulence were not properly assessed, therefore, reaching a conclusion on that topic could be risky. Nevertheless, based on other virulence studies with similar genotypes and death of some of the inoculated mice in present study we considered all the Argentinean human $T$. gondii isolates as potentially mild to high virulent strains. Future studies will be conducted in order to stablish strains virulence by using in vivo and in vitro assays.

Recent studies confirmed that serological examination of pregnant women improve management of treatment and minimize the sequelae of congenital toxoplasmosis on newborns $[7,18]$. Additionally, a comparison of different diagnostic methods for congenital toxoplasmosis performed in Argentina, showed that some cases could only be diagnosed by PCR and mice bioassay [19]. The parasite detection in seronegative individuals could be related with an acute infection and/or with immunodeficiency caused by other concomitant infections as well as modulations induced by the parasite strains [9]. Therefore, seronegative pregnant women should implement all suggested control measures and if they get infected during pregnancy they should receive specific treatment to minimize severity of congenital toxoplasmosis. It has been suggested that, besides time of maternal infection, the concentration of parasites, maternal/fetal immune response and $T$. gondii genotype are involved in the severity of congenital toxoplasmosis. In addition, know parasite genotype could help to determine the type of treatment, management and prognosis of baby/child infection [39]. Until now, 7 T. gondii isolates have been obtained from humans in Argentina, and all resulted atypical or non-clonal genotypes [27]. Obtaining new isolates from congenital toxoplasmosis and their molecular characterization will improve the knowledge on the epidemiological map of congenital toxoplasmosis in Argentina and South America.

According to the new paradigm [14,40], with identification of atypical strains circulating in our region and causing congenital toxoplasmosis, it will be important to perform the serological screenings according Argentine Consensus of Toxoplasmosis and to apply and monitoring treatments earlier in pregnancy. To achieve this aim, it is necessary to inform general population about $T$. gondii infection, diagnostics and control measures. These results should serve to generate awareness about congenital toxoplasmosis in South America.

\section{Conflict of interests}

All the authors declare any kind of conflict of interests.

\section{Acknowledgements}

We would like to thank Isidoro Ercoli, Selva Peñaloza and Ricardo Medina for their excellent technical assistance.

This research was partially funded by MINCYT, Argentina (grant PICT 2012/0355) and FCV-UNLP, Argentina (2016-2019-V250).

\section{References}

[1] J.P. Dubey (Ed.), Toxoplasmosis of Animals and Humans, Second edition, CRC Press, Boca Raton, Florida, 2010.

[2] G.E. Arce-Estrada, V. Gomez-Toscano, C. Cedillo-Pelaez, A.L. Sesman-Bernal, V. Bosch-Canto, J.L. Mayorga-Butron, J.A. Vargas-Villavicencio, D. Correa, Report of an unsual case of anophthalmia and craniofacial cleft in a newborn with Toxoplasma gondii congenital infection, BMC Infect. Dis. 17 (1) (2017) 459.

[3] R.A. Tazio Vanni, I.S. Ribeiro, C.A. Varella, B.A.L. Polanczyk, F.A.R. Kuchenbecker, Congenital toxoplasmosis: public health policy concerns, Braz. J. Infect. Dis. 12 (2) (2008) 107.

[4] K. Freeman, A. Salt, A. Prusa, G. Malm, N. Ferret, W. Buffolano, D. Schmidt, H.K. Tan, R.E. Gilbert, Association between congenital toxoplasmosis and parentreported developmental outcomes, concerns, and impairments, in 3 years old children, BMC Pediatr. 5 (2005) 23.

[5] F.M. Ruiz Lopes, D. Dib Gonçalves, R. Mitsuka-Breganó, R. Lemos Freire, I.T. Navarro, Toxoplasma gondii infection in pregnancy, Braz. J. Infect. Dis. 11 (5) (2007) 496-506.

[6] Anonim, Toxoplasmosis. OIE Terrestrial Manual (Chapter 2.9.10), (2008), pp. 1284-1293.

[7] L. Carral, F. Kaufer, P. Olejnik, C. Freuler, R. Durlach, Prevención de la toxoplasmosis congénita en un hospital de Buenos Aires, Medicina (Buenos Aires) 73 (2013) 238-242.

[8] F. Robert-Gangneux, It is not only the cat that did it: how to prevent and treat congenital toxoplasmosis, J. Infect. 68 (2014) 125-133.

[9] L.M. Weiss, K. Kim, Toxoplasma gondii. The Model Apicomplexan - Perspectives and Methods, ELSEVIER, United Kingdom, 2014, p. 1085.

[10] R. Durlach, F. Kaufer, L. Carral, C. Freuler, M. Ceriotto, M. Rodriguez, H. Freilij, 
J. Altcheh, L. Vazquez, R. Corazza, M.D. Fontana, H. Arienti, E. Sturba, S. Gonzalez Ayala, E. Cecchini, C. Salomon, M. Nadal, N. Gutierrez, E. Guarnera, Consenso Argentino de toxoplasmosis congénita, Medicina (Buenos Aires) 68 (2008) 75-87.

[11] H.F. Pena, S.M. Gennari, J.P. Dubey, C. Su, Population structure and mouse-virulence of Toxoplasma gondii in Brazil, Int. J. Parasitol. 38 (5) (2008) 561-569.

[12] C. Rajendran, C. Su, J.P. Dubey, Molecular genotyping of Toxoplasma gondii from Central and South America revealed high diversity within and between populations, Infect. Genet. Evol. 12 (2012) 359-368.

[13] L.M. Weiss, K. Kim, L.M.W.a.K. Kim (Ed.), Toxoplasma gondii the Model Apicomplexan: Perspectives and Methods, Elsevier Ltd., 2007, p. 800.

[14] L. Delhaes, D. Ajzenberg, B. Sicot, P. Bourgeot, M.L. Darde, E. Dei-Cas, V. HoufflinDebarge, Severe congenital toxoplasmosis due to a Toxoplasma gondii strain with an atypical genotype: case report and review, Prenat. Diagn. 30 (9) (2010) 902-905.

[15] J.E. Gómez Marín, J.D. Zuluaga, E.J. Pechené Campo, J. Triviño, A. De-La-Torre, Polymerase chain reaction (PCR) in ocular and ganglionar toxoplasmosis and the effect of therapeutics for prevention of ocular involvement in South American setting, Acta Trop. 184 (2018) 83-87.

[16] C. Silveira, C. Muccioli, G.N. Holland, J.L. Jones, F. Yu, A. Paulo, R.J. Belfort, Ocular Involvement following an Epidemic of Toxoplasma gondii Infection in Santa Isabel do Ivaí, Brazil, Am J. Ophthalmol. 159 (2015) 1013-1021 (e1013).

[17] J.P. Dubey, E.G. Lago, S.M. Gennari, C. Su, J.L. Jones, Toxoplasmosis in humans and animals in Brazil: high prevalence, high burden of disease, and epidemiology, Parasitology (2012) 1-50.

[18] J.D. Capobiango, R.M. Breganó, I.T. Navarro, C. Pereira Rezende Neto, A.M. Barbante Casella, F.M. Ruiz Lopes Mori, S. Pagliari, I. Teruo Inoue, E.M. Vissoci Reiche, Congenital toxoplasmosis in a reference center of Paraná, Southern Brazil, Braz. J. Infect. Dis. 14 (4) (2014) 364-371.

[19] L. Carral, F. Kaufer, L. Pardini, R. Durlach, G. Moré, M.C. Venturini, C. Freuler, Toxoplasmosis congénita: Diagnóstico serológico, RPC, aislamiento y caracterización molecular de Toxoplasma gondii, Rev. Chil. Infectol. 35 (1) (2018) $36-40$.

[20] S.Z. Haq, M.S. Abushahama, O. Gerwash, J.M. Hughes, E.A. Wright, M.S. Elmahaishi, Z.R. Lun, D. Thomasson, G. Hide, High frequency detection of Toxoplasma gondii DNA in human neonatal tissue from Libya, Trans. R. Soc. Trop. Med. Hyg. 110 (9) (2016) 551-557.

[21] G. Hide, E.K. Morley, J.M. Hughes, O. Gerwash, M.S. Elmahaishi, K.H. Elmahaishi, D. Thomasson, E.A. Wright, R.H. Williams, R.G. Murphy, J.E. Smith, Evidence for high levels of vertical transmission in Toxoplasma gondii, Parasitology 136 (14) (2009) 1877-1885.

[22] I. Martins Ribeiro Ferreira, J.E. Vidal, C. de Cássia Brandão de Mattos, L.C. de Mattos, D. Que, C. Su, V.L. Pereira-Chioccola, Toxoplasma gondii isolates: Multilocus RFLP-PCR genotyping from human patients in Sao Paulo State, Brazil identified distinct genotypes, Exp. Parasitol. 129 (2011) 190-195.

[23] G. Moré, L. Pardini, W. Basso, M. Machuca, D. Bacigalupe, M.C. Villanueva, G. Schares, M.C. Venturini, L. Venturini, Toxoplasmosis and genotyping of Toxoplasma gondii in Macropus rufus and Macropus giganteus in Argentina, Vet. Parasitol. 169 (1-2) (2010) 57-61.

[24] L. Pardini, G. More, M. Rudzinski, M.L. Gos, L.M. Campero, A. Meyer, M. Bernstein, J.M. Unzaga, M.C. Venturini, Toxoplasma gondii isolates from chickens in an area with human toxoplasmic retinochoroiditis, Exp. Parasitol. 166 (2016) 16-20.

[25] L. Pardini, A. Dellarupe, D. Bacigalupe, M.A. Quiroga, G. More, M. Rambeaud, W. Basso, J.M. Unzaga, G. Schares, M.C. Venturini, Isolation and molecular characterization of Toxoplasma gondii in a colony of captive black-capped squirrel monkeys (Saimiri boliviensis), Parasitol. Int. 64 (6) (2015) 587-590.

[26] G. Moré, P. Maksimov, L. Pardini, D.C. Herrmann, D. Bacigalupe, A. Maksimov, W. Basso, F.J. Conraths, G. Schares, M.C. Venturini, Toxoplasma gondii infection in sentinel and free-range chickens from Argentina, Vet. Parasitol. 184 (2-4) (2012) 116-121.

[27] L. Pardini, L.A. Carral, M. Bernstein, M.L. Gos, P. Olejnik, J.M. Unzaga, F.J. Kaufer, C.B. Freuler, R.A. Durlach, M.C. Venturini, First isolation and molecular characterization of Toxoplasma gondii from a human placenta in Argentina, Parasitol. Int. 63 (2014) 470-472.

[28] C. Su, X. Zhang, J.P. Dubey, Genotyping of Toxoplasma gondii by multilocus PCRRFLP markers: a high resolution and simple method for identification of parasites, Int. J. Parasitol. 36 (7) (2006) 841-848.

[29] D.K. Howe, S. Honore, S. Derouin, L.D. Sibley, Determination of genotypes of Toxoplasma gondii strains isolated from patients with toxoplasmosis, J. Clin. Microbiol. 35 (1997) 1411-1414.

[30] D.K. Howe, L.D. Sibley, Toxoplasma gondii comprises three clonal lineages: correlation of parasite genotype with human disease, J. Infect. Dis. 172 (1995) 1561-1566.

[31] M. Bernstein, L. Pardini, G. Moré, J.M. Unzaga, C. Su, M.C. Venturini, Population structure of Toxoplasma gondii in Argentina, Infect. Genet. Evol. 65 (2018) 72-79.

[32] L.D.d. Barros, A. Taroda, D.L. Zulpo1, I.A.L.d. Cunha, A.S. Sammi, S.T. Cardim, A.C. Miura, C. Su, R.Z. Machado, O. Vidotto, J.L. Garcia, Genetic characterization of Toxoplasma gondii isolates from eared doves (Zenaida auriculata) in Brazil, Braz. J. Vet. Parasitol. Jaboticabal. 23 (4) (2014) 443-448.

[33] J.P. Dubey, J.A. Cortés-Vecino, J.J. Vargas-Duarte, N. Sundar, G.V. Velmurugan, L.M. Bandini, L.J. Polo, L. Zambrano, L.E. Mora, O.C.H. Kwok, T. Smith, C. Su, Prevalence of Toxoplasma gondii in dogs from Colombia, South America and genetic characterization of T. gondii isolates, Vet. Parasitol. 145 (2007) 45-50.

[34] J.P. Dubey, S.M. Gennari, N. Sundar, M.C. Vianna, L.M. Bandini, L.E. Yai, C.H. Kwok, C. Suf, Diverse and atypical genotypes identified in Toxoplasma gondii from dogs in Sao Paulo, Brazil, J. Parasitol. 93 (1) (2007) 60-64.

[35] J.P. Dubey, G.V. Velmurugan, C. Rajendran, M.J. Yabsley, N.J. Thomas, K.B. Beckmen, D. Sinnett, D. Ruid, J. Hart, P.A. Fair, W.E. McFee, V. ShearnBochsler, O.C. Kwok, L.R. Ferreira, S. Choudhary, E.B. Faria, H. Zhou, T.A. Felix, C. Su, Genetic characterisation of Toxoplasma gondii in wildlife from North America revealed widespread and high prevalence of the fourth clonal type, Int. J. Parasitol. 41 (11) (2011) 1139-1147.

[36] L.A. Silva, R.O. Andrade, A.C. Carneiro, R.W. Vitor, Overlapping Toxoplasma gondii genotypes circulating in domestic animals and humans in Southeastern Brazil, PLoS One 9 (2) (2014) e90237.

[37] A. Khan, B. Fux, C. Su, J.P. Dubey, M.L. Darde, J.W. Ajioka, B.M. Rosenthal, L.D. Sibley, Recent transcontinental sweep of Toxoplasma gondii driven by a single monomorphic chromosome, Proc. Natl. Acad. Sci. U. S. A. 104 (37) (2007) 14872-14877.

[38] D. Ajzenberg, A. Dumetre, M.L. Darde, Multiplex PCR for typing strains of Toxoplasma gondii, J. Clin. Microbiol. 43 (4) (2005) 1940-1943.

[39] C.P. Rico-Torres, J.A. Vargas-Villavicencio, D. Correa, Is Toxoplasma gondii type related to clinical outcome in human congenital infection? Systematic and critical review, Eur. J. Clin. Microbiol. Infect. Dis. 35 (7) (2016) 1079-1088.

[40] D.S. Lindsay, J.P. Dubey, Toxoplasma gondii: the changing paradigm of congenital toxoplasmosis, Parasitology 138 (14) (2011) 1829-1831. 